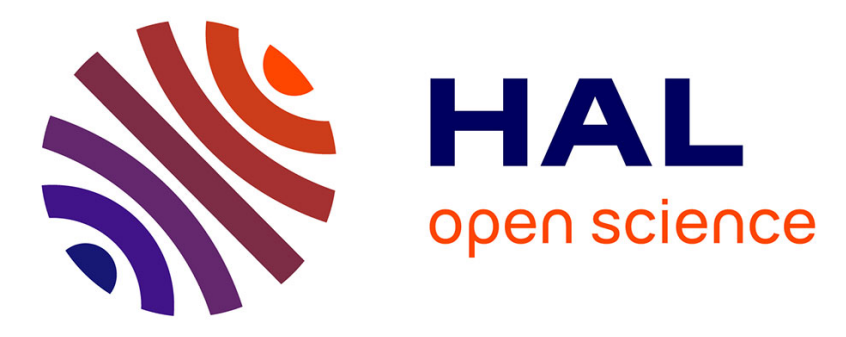

\title{
Methodology for water monitoring in the upper troposphere with Raman lidar at the Haute-Provence Observatory
}

Christophe Hoareau, Philippe Keckhut, Alain Sarkissian, Jean-Luc Baray, Georges Durry

\section{To cite this version:}

Christophe Hoareau, Philippe Keckhut, Alain Sarkissian, Jean-Luc Baray, Georges Durry. Methodology for water monitoring in the upper troposphere with Raman lidar at the Haute-Provence Observatory. Journal of Atmospheric and Oceanic Technology, 2009, 26 (10), pp.2149-2160. 10.1175/2009JTECHA1287.1 . hal-00408531

\section{HAL Id: hal-00408531 \\ https://hal.science/hal-00408531}

Submitted on 8 May 2016

HAL is a multi-disciplinary open access archive for the deposit and dissemination of scientific research documents, whether they are published or not. The documents may come from teaching and research institutions in France or abroad, or from public or private research centers.
L'archive ouverte pluridisciplinaire HAL, est destinée au dépôt et à la diffusion de documents scientifiques de niveau recherche, publiés ou non, émanant des établissements d'enseignement et de recherche français ou étrangers, des laboratoires publics ou privés. 


\title{
Methodology for Water Monitoring in the Upper Troposphere with Raman Lidar at the Haute-Provence Observatory
}

\author{
Christophe Hoareau, Philippe Keckhut, and Alain SARKissian \\ LATMOS, Université Versailles Saint-Quentin, Verrières-le-Buisson, France \\ JEAN-LUC BARAY \\ LACy, Université de La Réunion, La Réunion, France \\ GEORGES DURRY \\ GSMA, Université de Reims, Champagne Ardenne, France
}

(Manuscript received 28 January 2009, in final form 5 June 2009)

\begin{abstract}
A Raman water vapor lidar has been developed at the Haute-Provence Observatory to study the distribution of water in the upper troposphere and its long-term evolution. Some investigations have been proposed and described to ensure a pertinent monitoring of water vapor in the upper troposphere. A new method to take into account the geophysical variability for time integration processes has been developed based on the stationarity of water vapor. Successive measurements, considered as independent, have been used to retrieve $\mathrm{H}_{2} \mathrm{O}$ profiles that were recorded during the same nighttimes over a few hours. Various calibration methods, including zenith clear-sky observation, standard meteorological radiosondes, and total water vapor column, have been investigated. A method to evaluate these calibration techniques has been proposed based on the variance weakening. For the lidar at the Haute-Provence Observatory, the calibration based on the total water vapor column appears to be the optimum method. Radiosondes also give comparable results, but do not allow lidar to be independent. The clear-sky zenith observation is an original technique, and seems to accurately identify discontinuities. However, it appears to be less reliable, based on the variance investigation, than the two others. It is also sensitive to aerosol loading, which is also expected to vary with time.
\end{abstract}

\section{Introduction}

Water vapor is a key atmospheric constituent in the global radiation budget and it plays the main role because of its efficiency as a greenhouse gas. Despite its distribution in the atmosphere and its importance for the climate system, many questions regarding $\mathrm{H}_{2} \mathrm{O}$ are presently unresolved (Bates et al. 2008), including the stratospheric water vapor trends. In the stratosphere water vapor has increased 2 ppmv since the 1950s, which is not negligible compared to the mean values observed in this region (4-6 ppmv; Kley et al. 2000). The water vapor distribution in the upper troposphere (UT) and

Corresponding author address: Christophe Hoareau, LATMOS, Réduit de Verrières-BP 3, Route des Gatines, 91371 Verrières-leBuisson CEDEX, France.

E-mail: christophe.hoareau@latmos.ipsl.fr lower stratosphere (LS) is not perfectly understood towing to the numerous processes involved, high spatiotemporal variability, phase changes, and the transport processes. It is then essential to improve our knowledge about water vapor in this region of the atmosphere with adequate resolution.

Given the difficulties to measure accurately water vapor in the UT-LS, a large number of techniques have been developed (microwave, GPS, specific sondes, radar, lidar, etc.). Many of them cannot provide long-term monitoring of water vapor (Durry and Pouchet 2001). The lidar instrument allows continuous probing of water vapor with good sensitivity and vertical resolution. The Raman lidar presents the advantage of being implemented in existing backscattering lidar; since the work of Cooney (1970), a larger community of researchers has been using these additional channels (Sherlock et al. 1999a; Leblanc et al. 2008; Ferrare et al. 1995; Sakai et al. 
2007). However, calibration issues are still pending; indeed, a proper calibration is necessary to provide an absolute measurement of water vapor mixing ratio. The calibration coefficients are commonly determined from nearby meteorological radiosondes, but their reliability for long-term continuity is questionable (Soden and Lanzante 1996) and independent techniques are preferred. Other methods also need to be evaluated (Sherlock et al. 1999b; Leblanc and McDermid 2008), including the one proposed by Sherlock et al. (1999b) based on daytime zenith sky observations.

Because Raman signals are small compared to elastic backscattered signals, long integration times are required to accurately cover the upper troposphere. Averaging processes reduce the variability scale but also mix several situations that may not exist simultaneously. That is a problem for water vapor climatology investigations. Nevertheless, the possibility to acquire an elastic signal simultaneously with water vapor Raman signals is of great interest for the sounding the the upper troposphere and also provide information about ice crystal occurrence.

In this study, a comparison between various methods used to achieve calibration is presented and their respective limitations are discussed. This issue is essential for long-term monitoring and trend studies of water vapor in the upper troposphere. In section 2, a brief description of the lidar instrument deployed at the HauteProvence Observatory (hereafter OHP) in southern France and the associated data analysis are presented. In section 3, a method to average lidar echos according to the variability is proposed. Finally, in section 4, three different calibration methods are reported and compared.

\section{Lidar description and analysis}

\section{a. Description of the lidar implemented at the Haute-Provence Observatory}

The Raman lidar water vapor implemented at the Haute-Provence Observatory $\left(43.9^{\circ} \mathrm{N}, 5.7^{\circ} \mathrm{E}\right.$, elevation $685 \mathrm{~m}$ ) is an upgrade of the receiving optics of the existing Rayleigh temperature lidar that is part of the Network for the Detection of Atmospheric Composition Change (NDACC), and operates on a routine basis at night except in the presence of low cloud (Sherlock et al. 1999a). An Nd:YAG laser pulse at $532.1 \mathrm{~nm}$ is emitted vertically through the atmosphere at a rate of $50 \mathrm{~Hz}$. The backscattered signals are collected by optical fibers mounted in the focal plane of a four-telescope mosaic of $0.5-\mathrm{m}$ diameter each and transferred to the optical ensemble. A small field of view of $0.5 \mathrm{mrad}$ is used to reduce the sky background at maximum, even if

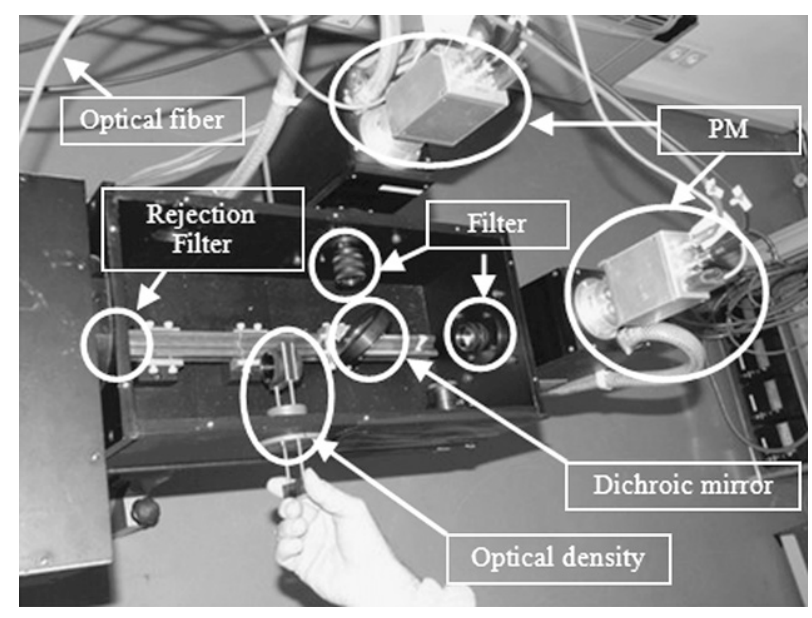

FIG. 1. Open view of the receiving optical box (including photomultipliers, filters, and dichroic mirror) and the manual slot used for daytime signal reduction for $\mathrm{N}_{2}$ and $\mathrm{H}_{2} \mathrm{O}$ Raman channels [Mollet-Centre National de la Recherche Scientifique (CNRS)].

the measurements are essentially performed at nighttime. The parallax design (emission-reception axis of $0.6 \mathrm{~m}$ ) of this lidar exhibits a dead altitude zone from the ground up to $2-3 \mathrm{~km}$ as a consequence of the small field of view. The Raman-shifted lines $\mathrm{H}_{2} \mathrm{O}(660 \mathrm{~nm})$ and $\mathrm{N}_{2}$ $(607 \mathrm{~nm})$ are separated by a dichroic mirror (Fig. 1), and are detected by means of photomultiplier tubes (PMTs) operated in photon-counting mode. Counts from 8000 shots ( $\sim 2 \mathrm{~min} 40 \mathrm{~s})$ are preaccumulated in $75-\mathrm{m}(0.5 \mu \mathrm{s})$ bin intervals and stored to constitute the raw data.

Sherlock et al. (1999a) have shown that absorption and fluorescent reemission of the energy associated with the elastic backscatter-return signals can also give rise to a systematic bias in Raman Stokes water vapor measurements. This systematic bias has been corrected by the fiber-optic cables replacement (OH-rich optical fibers are now used); consequently, the clear-sky fluorescence bias has been reduced to less than $5 \times 10^{-6} \mathrm{~kg} \mathrm{~kg}^{-1}$ of dry air. The contributions of Rayleigh-Mie and Raman $\mathrm{N}_{2}$ backscatter have been reduced with an appropriate choice of optics, increasing the 532-nm rejection and minimizing this bias. The error due to rejection was shown to induce a contribution inferior to $0.1 \%$ (Sherlock et al. 1999a). The calibration measurements with the daytime zenith observations were performed regularly over a long period of time and constitute a suitable database. Because these measurements are realized during the day (solar zenith angle $60^{\circ}$ ), a neutral density filter is included in the optic path of the return signal, which reduces the signal by a factor of 100 , to provide similar conditions than during nighttime and avoid an oversaturation of the counting detection (Fig. 1). The elastic 




FIG. 2. Examples of Raman $\mathrm{H}_{2} \mathrm{O}, \mathrm{N}_{2}$, and Rayleigh-Mie backscatter signals.

signal is two orders of magnitude larger than the Raman nitrogen signal, which is also larger than water vapor Raman signal by two orders of magnitude (Fig. 2). The noise level is equal for the first two channels to $2 \times$ $10^{-4}$ photons $/ \mathrm{shot} / \mu \mathrm{s}$, whereas the Raman channel is one order of magnitude smaller owing to the use of two successive $\mathrm{H}_{2} \mathrm{O}$ interference filters (the bandwidths of the interference filters are $1 \mathrm{~nm}$ ). The example shown in Fig. 2 indicates that the altitude range is around $10 \mathrm{~km}$ in this case.

\section{b. Measurement errors analysis}

Because systematic errors have been reduced by hardware design, the signal processing related to measurement uncertainties is based on random errors (Sherlock et al. 1999a). The two principal error sources considered here are photon counting and skylight background estimation. The photon-counting process is described by Poisson statistics, and the standard deviation of the measurement is $\sigma=\sqrt{N}$, where $N$ is the number of photons counted. The skylight background noise, $b_{x}$, is due to skylight brightness, thermal noise of the multiplier, and signal-induced noise of a large initial burst. The background noise signal is approximated by a least squares fitting method. The noise model is an issue for the upper-tropospheric range (altitude $75-150 \mathrm{~km}$ ) where the signal is small compared to noise. A quadratic function is chosen and this method appears to be quite stable. This has been validated through comparisons with nearby high-resolution diode laser sondes (described in section $2 \mathrm{~d}$ ).

To reduce the statistical noise a temporal and vertical integration has been applied on raw data, which extends the altitude range in the upper troposphere. The mini-

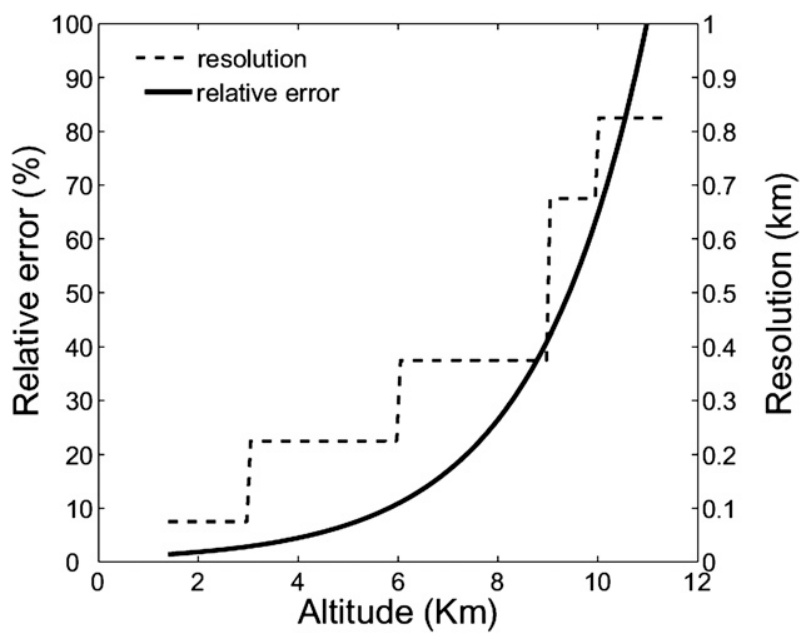

FIG. 3. Mean relative errors and vertical resolution as a function of the altitude.

mum integration time that we decided to use is $\sim 25 \mathrm{~min}$; it is the best compromise to access the variability. The vertical integration is an averaging window increasing with altitude, as illustrated in Fig. 3. Thus, in the lower troposphere, since the return signal is large, the initial $75 \mathrm{~m}$ are not degraded. In the middle and upper troposphere, the vertical resolution increases up to $1 \mathrm{~km}$. Random errors increase to $10 \%$ at $6 \mathrm{~km}$ and can increase up to $60 \%$ at around $10 \mathrm{~km}$.

\section{c. Data analysis}

The water vapor mixing ratio is based on the ratio of the $\mathrm{H}_{2} \mathrm{O}$ Raman $(660 \mathrm{~nm})$ and the $\mathrm{N}_{2}$ Raman $(607 \mathrm{~nm})$ signals, as described by Sherlock et al. (1999a), accounting for the atmospheric differential transmission $\Gamma(z)$ and the calibration coefficient $C$ :

$$
q(z)=C \Gamma(z) \frac{S_{\mathrm{H}_{2} \mathrm{O}}(z)}{S_{\mathrm{N}_{2}}(z)} .
$$

In the middle and upper troposphere aerosols densities are generally small and ice clouds do not exhibit large wavelength attenuation dependence. Although it can be estimated with additional channels (Faduilhe et al. 2005), it has been shown that the relative transmission of the Raman returns corresponds to a $0 \%-5 \%$ overestimation in extreme aerosol loading conditions. Furthermore, for altitudes above $4 \mathrm{~km}$ the vertical gradient of $\Gamma(z)^{-1}$ is small $\left(<0.2 \% \mathrm{~km}^{-1}\right)$ and negligible; consequently, no attenuation corrections have been applied (Sherlock et al. 1999a).

The optical thickness of cirrus is calculated in accordance with the scattering ratio profile (SR), which is determined by the following expression: 


$$
\mathrm{SR}=\frac{\beta_{\text {aerosol }}(\lambda, z)+\beta_{\text {rayleigh }}(\lambda, z)}{\beta_{\text {rayleigh }}(\lambda, z)},
$$

where $\beta_{\text {aerosol }}(\lambda, z)$ and $\beta_{\text {rayleigh }}(\lambda, z)$ are the Mie and Rayleigh backscattering coefficients. Because molecular backscattering can be estimated by a dry air density profile, it can further be retrieved from the nitrogen signal, so SR can be derived from the ratio between the return signal at $532 \mathrm{~nm}$ and the nitrogen Raman signal (Ferrare et al. 2001).

The optical thickness of cirrus, $\tau_{\text {cirrus }}$, is calculated using a method similar to that described by Goldfarb et al. (2001), where $\tau_{\text {cirrus }}$ can be expressed by the following expression:

$\tau_{\text {cirrus }}=(\mathrm{LR}) \sigma_{\text {rayleigh }} \int_{Z_{\min }}^{Z_{\max }} n_{\text {air }}(z)(\operatorname{SR}(z)-1) d z$,

where $\beta_{\text {rayleigh }}=\sigma_{\text {rayleigh }} n_{\text {air }}(z)$ and the air density number $n_{\text {air }}(z)$ are calculated by the Mass Spectrometer Incoherent Scatter-Extended-1990 (MSISE-90) atmospheric model. A lidar ratio (LR) of $18.2 \mathrm{sr}$ (Platt and Dilley 1984) is used, and $\sigma_{\text {rayleigh }}(532 \mathrm{~nm})=5.7 \times$ $10^{-32} \mathrm{~m}^{2} \mathrm{sr}^{-1}$.

\section{d. Comparison between lidar and diode laser spectrometer}

The tunable diode laser spectrometer [SLDA (French acronym)] is a balloon-borne near-infrared diode laser spectrometer devoted to the in situ monitoring of methane and water vapor in the upper troposphere and the lower stratosphere by absorption spectroscopy (Durry and Pouchet 2001; Durry and Megie 1999, 2000). The SDLA instrument is able to provide a mixing-ratio vertical profile with good vertical resolution $(\sim 50 \mathrm{~m})$ and a precision error within $5 \%-10 \%$. The dynamic range for the measurements is four orders of magnitude, corresponding to the water vapor changes in the UT-LS. In June 2000, the diode laser spectrometer was launched from a stratospheric balloon at Gap in southern France $\left(44^{\circ} \mathrm{N}, 6^{\circ} \mathrm{E}\right)$, Gap being located roughly at $100 \mathrm{~km}$ from the OHP (Durry and Pouchet 2001). The water vapor mixing ratio profiles obtained during the ascent of the SDLA are used here so as to validate lidar profiles at OHP in the upper troposphere (Fig. 4). In this validation case, the calibration is realized with meteorological radiosonde data from Nîmes, France, in the 3-6 km range.

\section{Data sampling}

For stationary atmospheric conditions, the backscattered photons hit the counter independently and the



FIG. 4. Lidar-Tunable Diode Laser Spectrometer (TDLS) intercomparison.

counting is a Poisson process. As discussed in section 2, the sampling period must be long enough for collecting a sufficient number of counts $(\sim 25 \mathrm{~min})$ to provide the best statistical estimator of the water vapor mixing ratio. However, if the sampling period is too long, information about the variability of the local concentration is lost. Moreover, from a statistical point of view, the mixing ratio derived from the signal averaging is equivalent to the averaging of the individual mixing ratio profiles, assuming that the signal follows the stationary atmospheric hypothesis. This last consideration is already considered for cloud particle counter analysis (Davis et al.1996). The stationary condition is widely ignored in analyzing atmospheric lidar data, but it may be important. Even the simplest statistical properties, such as variance and autocorrelation, become ambiguous at best and meaningless at worst if the data are not stationary. The computed variance based on the Poisson theory is underestimated in the case of lidar because the noise is not only instrumental but also related to atmospheric variability. This additional variance owing to atmospheric fluctuations is of particular importance for the interpretation of instrumental intercomparison. As the lidar probes a moving fluid, the atmospheric composition can change suddenly with random processes. This is particularly pertinent for fronts and cloud motion or for the transport of chemical components through long tongues (or filaments) observed at midlatitude in the stratosphere or in the troposphere during stratospheric air intrusions. Also, it is necessary to identify these different situations if air masses from various origins cannot be averaged. Assuming a stationary condition is not realistic, 



FIG. 5. Evolution of optical thickness and raw mixing ratio: $\mathrm{H}_{2} \mathrm{O} / \mathrm{N}_{2}$.

the proposed methodology is to identify a priori periods of quasi-stationary conditions regarding statistical variability and perform averaging on these given periods. Although a minimum number of counts is required to obtain a reasonable accuracy in the upper troposphere, some transition periods may be eliminated from the database.

To get a reasonable compromise between accuracy and atmospheric variability, the proposed method consists of adjusting the integration time with the discontinuity of the flow sounded. To achieve this goal, the series of the ratio of the raw data has been statistically investigated to identify discontinuities at several altitude heights.

The analysis is conducted for three altitude ranges (3-5, $6-7$, and $7-11 \mathrm{~km})$. For each altitude range and each integrated profile (over 2 min $40 \mathrm{~s}$ ), the vertically integrated value of water vapor content is performed. Nevertheless this procedure is only done for the altitude ranges 3-5 and 6-7 $\mathrm{km}$ because at higher altitudes water vapor density is weak. Since it is difficult to correctly determine this value between 7 and $11 \mathrm{~km}$ and the system is limited for measuring $\mathrm{H}_{2} \mathrm{O}$ at higher altitudes, the analyses of the cirrus optical thickness series in this altitude range is preferred to represent the variability. To determine the optical thickness we used the method described in section 2c. Identification of discontinuities in the time series is based on the test of nonstationarity of the series due to a change in dispersion (variance). The procedure applied is an iterative method designed to research the multiple change points in arbitrary value series (Lanzante 1996). This method is based on the method of the nonparametric (Wilcoxon-Mann-Whitney distributional) test, followed by an adjustment of the median; the process is reiterated until a significant continuity is achieved (Fig. 5).

Depending on the periods analyzed, from two to five periods can be identified during a complete night. Considering that two successive profiles give a variability of the same order, each profile can be hence considered as independent measurements. An example is given in Fig. 6. For the scattering profiles, raw individual profiles can be considered. However, if a simultaneous study of water vapor and ice phase needs to be conducted, the scattering profiles can be derived for the same period as water vapor (Fig. 7).

\section{Calibration methods}

The application of lidar measurements to climatological study requires a robust calibration of the instrument. The evolution of the calibration coefficient over a long enough period permits one to adjust the series to instrumental changes that are unavoidable in a long commitment (ageing and/or substitution of filters, fiberoptic, receiving optic alignment, detectors, etc.). In this section, three calibration methods are described and compared over the period from May 1999 to December 2000.

\section{a. Calibration from passive zenith daytime observations}

One of the methods of calibration used here is based on the systematic observation of the sky with the lidar having the laser off and the neutral density filter on, as developed by Sherlock et al. (1999b). The ratio of the two Raman channels during daytime provides useful 

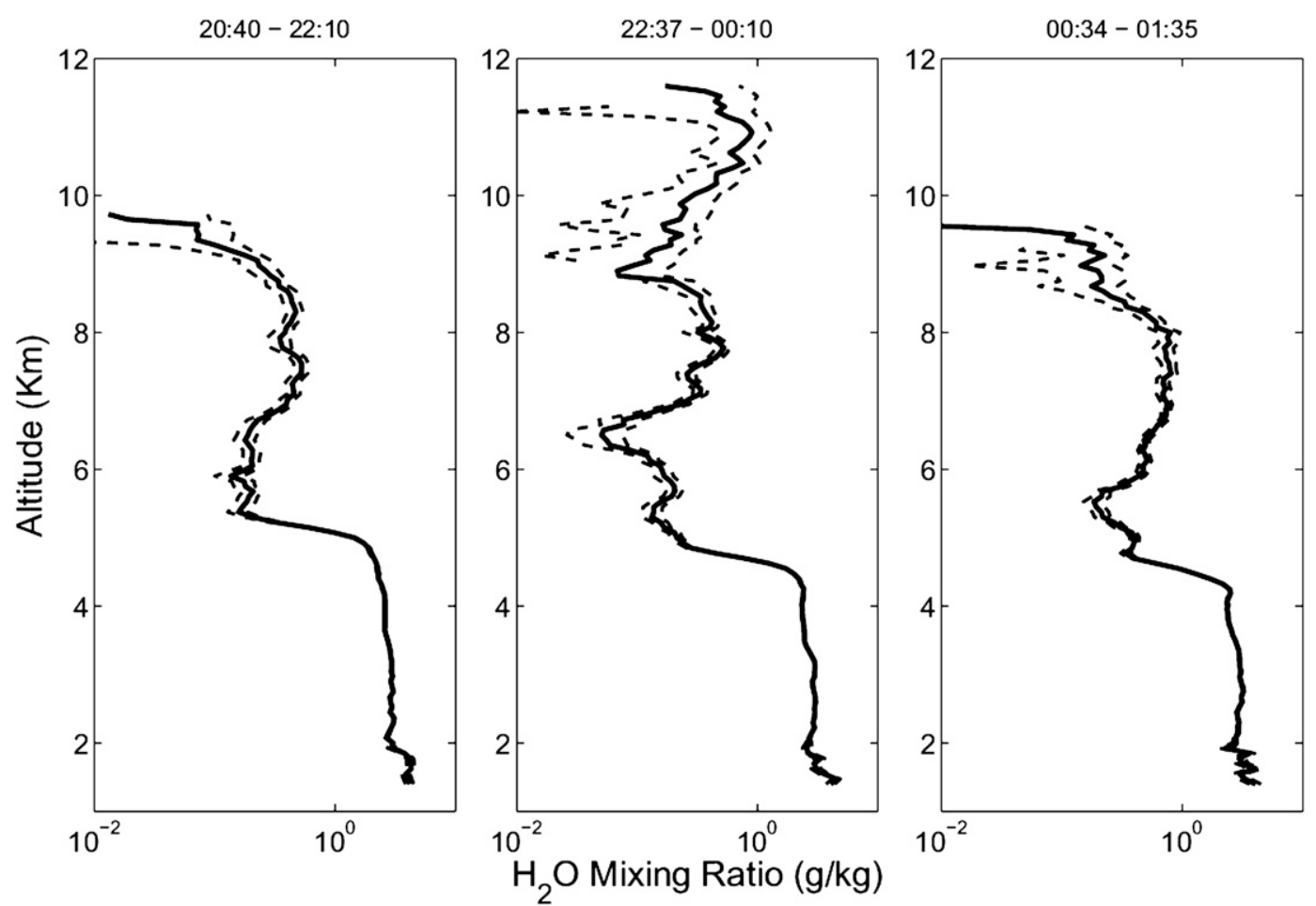

FIG. 6. Vertical profiles of water vapor obtained by lidar during the same night of measurements.

information about the nighttime calibration coefficient. This method assumes that the calibration coefficient is stable and mainly due to instrumental changes and that the daytime measurements are correlated with nighttime laser observations. The instrument function, expressed as the lidar calibration coefficient, can be given by the product of two terms [Eq. (4)], the instrumental transmission, the detection efficiency, and the wavelengthdependent convolution of the Raman backscatter cross sections with the instrument function:

$$
C^{\prime}=\frac{T_{\mathrm{N}_{2}}}{T_{\mathrm{H}_{2} \mathrm{O}}} \frac{\int I_{\mathrm{N}_{2}}(\lambda) \sigma_{\mathrm{N}_{2}}(\lambda) d \lambda}{\int I_{\mathrm{H}_{2} \mathrm{O}}(\lambda) \sigma_{\mathrm{H}_{2} \mathrm{O}}(\lambda) d \lambda},
$$

where $T$ is transmission of the optical components, $I$ the wavelength dependence of the instrument function, and $\sigma$ the Raman backscatter cross sections. The measurement of the zenith sky luminance during daytime as the ratio of the two channels has been shown to follow radiative modeling quite well (Sherlock et al. 1999b). When the sun is high above the horizon, the ratio is quite constant. However, to be able to keep the same solar zenith angle for a midlatitude location, a value of $60^{\circ}$ has been chosen: it is at the boundary between the maximum elevation angle and the ascending values. The main limitation of this method is the effect of aerosols and clouds. Measurements are then conducted at a given time, changing with season to keep the same solar zenith angle for clear-sky conditions. Cirrus effects are easy to identify, but a slow increase in aerosol loading is the major limitation of the method, despite that the aerosol column can be measured independently with the collocated sun photometer.

\section{b. Calibration using collocated radiosonde measurements}

Determining the lidar profile mixing-ratio calibration coefficient using radiosondes is the easiest approach. However, knowing the numerous problems of discontinuities at individual stations (humidity sensor response, material change, etc.) and the poor sensitivity in the upper troposphere, this method (calibration with radiosonde) does not appear to be an optimal method and is questionable for independent long-term lidar monitoring. However, it is valuable to compare this approach with other methods. Owing to the very high spatial and temporal variability of water vapor, calibration studies are more appropriate if the measurements are taken simultaneously and from the same location. In this analysis, we have considered the radiosondes at Nîmes (distance between Nîmes and the OHP $<100 \mathrm{~km}$ ) for the calibration. The raw lidar signals are integrated over a time period of at least $25 \mathrm{~min}$ close to the radiosonde measurement times and accounting for the variability 

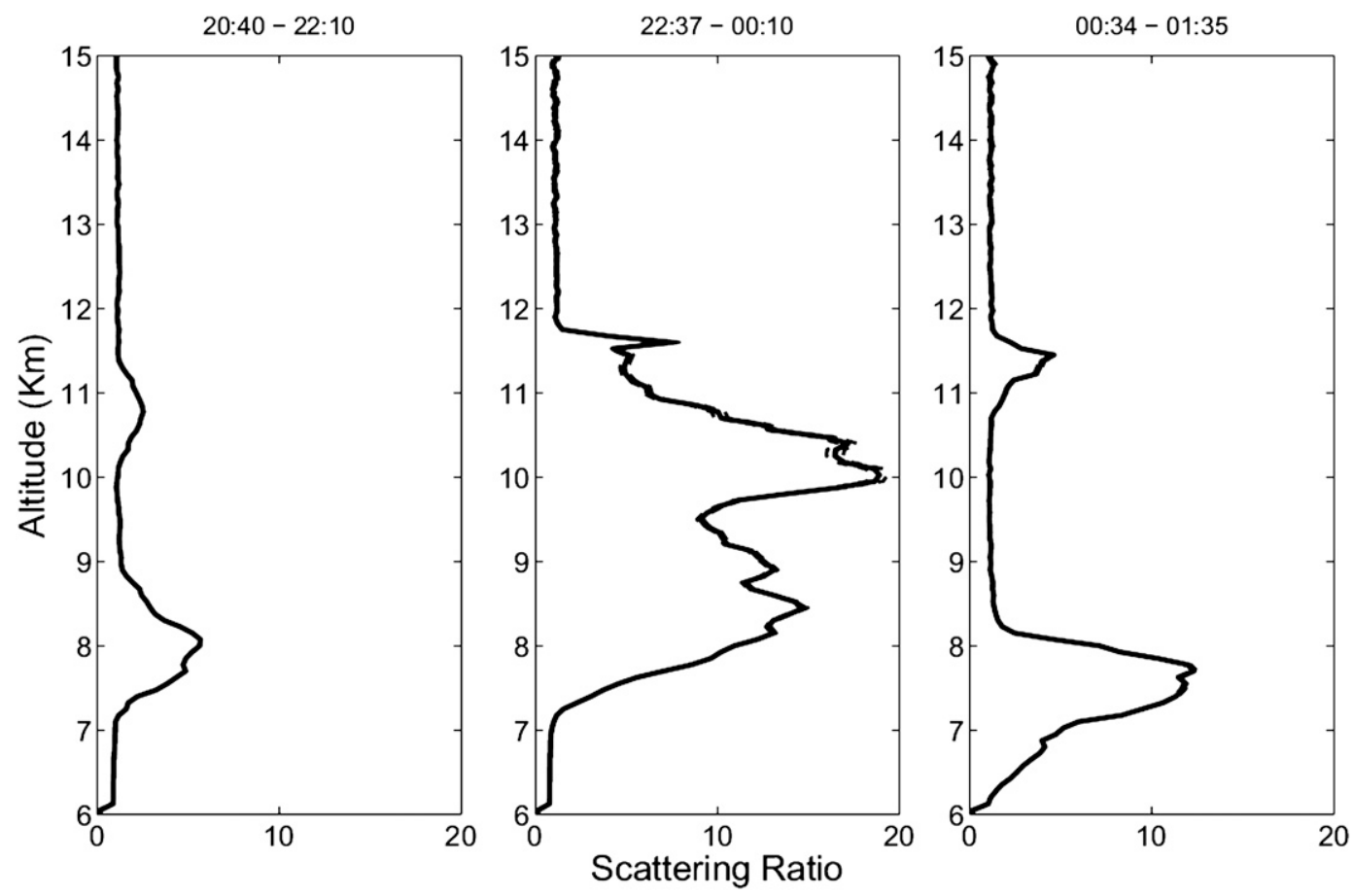

FIG. 7. Vertical profiles of the scattering ratio obtained by lidar during the same night of measurements.

following the procedure described in section 3. To compare and calibrate lidar profiles with radiosonde profiles, relative humidity data measured by radiosonde were converted to water vapor mixing ratio by means of the empirical saturation vapor pressure over liquid water formulas of Hyland and Wexler (1983). The calibration coefficient computation is determined from the median of the ratio of mixing ratio profiles, lidar to radiosonde, in the altitude range from 3 to $6 \mathrm{~km}$. This altitude range appears to be the most useful because the data recovery between the laser beam and the collecting area operate for altitudes between 2.5 and $3 \mathrm{~km}$. At low relative humidity and low temperature the radiosondes sensors are less reliable (sensor characteristics, response time, etc.). Also the random error of the return lidar signal becomes more important above $7 \mathrm{~km}$. For these reasons, we limit the upper altitude at $6 \mathrm{~km}$.

\section{c. Calibration method with total column measurements}

The use of total column measurements for lidar profile calibration is a general method that can be achieved with different ancillary data: GPS, Fourier transform infrared (FTIR), and radiometer. This method is possible if the lidar profiles cover the altitude range where water vapor is distributed. The water vapor content is located $\sim 99 \%$ in the troposphere. As the lidar profile is optimized for the upper troposphere, there is no measure- ment below 2-3 km. Because balloon measurements are quite reliable in the lower troposphere, the lidar profile is extended downward using the radiosondes after being used to normalize lidar profiles. Above the top of the lidar profile, an upward extension is made based on a climatology that used Halogen Occultation Experiment (HALOE) and Microwave Limb Sounder (MLS) data because this additional water vapor contribution is quite small. The water vapor total column is determined by the following equation:

$$
N_{\mathrm{H}_{2} \mathrm{O} \text {, lidar }}=\frac{V_{\text {int }}\left(M R_{\mathrm{H}_{2} \mathrm{O}}\right) \times N_{A}}{M_{\mathrm{H}_{2} \mathrm{O}} \times 10^{4}},
$$

where $V_{\text {int }}$ is the integrated value of $\mathrm{H}_{2} \mathrm{O}$ lidar profile in grams per square meter, $N_{A}$ the Avogadro number, and $M_{\mathrm{H}_{2} \mathrm{O}}$ the molecular mass of water.

Here, the water vapor total column is obtained from

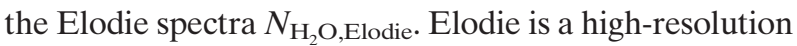
visible spectrometer $(285-680 \mathrm{~nm})$ mounted on the 1.93-m telescope of the Haute-Provence Observatoryused in astrophysics and planetology and operated between 1995 and 2005 (Moultaka et al. 2004). Water vapor is measured at $593 \mathrm{~nm}$ by absolute optical absorption spectrometry (Sarkissian and Slusser 2009). When the spectrometer is not pointing most of the time at $30^{\circ}$ zenith angle toward the south (when stars cross the meridian), then the total column measurement obtained by Elodie 




FIG. 8. Evolution of the calibration coefficient values $C_{0}$ obtained from the calibration method using a solar zenith angle between $62^{\circ}$ and $65^{\circ}$.

is divided by an air mass factor $\left(1 / \cos 30^{\circ}\right)$, which provides a vertical column that could be compared with lidar. Note that the air volume observed by the vertical column that could be compared with lidar and Elodie are, at the altitude of $5 \mathrm{~km}$, less than $1.7 \mathrm{~km}$ away.

\section{d. Comparison of calibration methods}

The evolution of the coefficient values determined from the zenith clear-sky observations $\left(C_{0}\right)$ (Fig. 8) seems to be the most appropriate to detect instrumental effects because the noise is quite small and some discontinuities can be easily detected (Table 1). The relative amplitude observed between the maximum value of the median and the minimum value is 1.4 , and the mean variance is less than $1 \%$. The calibration coefficients deduced by comparisons with radiosondes $\left(C_{1}\right)$ (Fig. 9) reveal many similarities on the discontinuity events, except for June-July 2000. Also, the instrumental discontinuity during October 1999-April 2000 is less clear than the clear-sky zenith observations with a mean variance observed of $\sim 11 \%$. According to this method of calibration, the relative amplitude observed between the maximum value of the median and the minimum value is 2.4. The calibration coefficient using total column (and radiosondes to extend the lidar profile) shows a systematic overestimation of water vapor content, probably due to the memory effect of the radiosonde (Fig. 10). The few numbers of calibrations and the overall noise on the coefficient evolution cannot establish a real comparison with the other methods. The discontinuity during JuneJuly 2000 is also not detected with the total column method and the November 1999-April 2000 period seems to be slightly overestimated according to this last method. The results of this study seem to suggest the following conclusion: the procedure of extending the lidar profiles in the lower altitudes through radiosonde is required but could result in a bias of the estimated columnar values toward the radiosonde and, consequently, it could result in bias on the retrieved calibration constant. Bias could be due to the inhomogeneities of radiosonde series (Soden and Lanzante 1996), and could explain why the method of calibration using radiosondes does not perfectly detect all the discontinuities owing to instrumental changes in the lidar. However, even if no major changes of the humidity sensor have been noted, the readjustment by the total column method seems to improve the overall continuity. On the other hand, uncertainties of the approximation of the water vapor total column measurement by the spectrometer because of, for example, the noncoincident time could also introduce noise in the calibration constant.

To perform a more quantitative estimate of the calibration coefficients, the lidar water vapor mixing ratio

TABLE 1. Major instrumental changes for the period May 1999-December 2000.

\begin{tabular}{ll}
\hline \multicolumn{1}{c}{ Date } & \multicolumn{1}{c}{ Instrumental changes } \\
\hline 13 Sep 1999 & Emission modification and telescope adjustment \\
29 Nov 1999 & Change of counting system \\
13 Jan 2000 & Telescope adjustment \\
31 Jan 2000 & New alignment in the optical box \\
9 Jun 2000 & Telescope adjustment \\
26 Jul 2000 & Optical fiber change $(0.9$ to $1.5 \mathrm{~mm})$ \\
\hline
\end{tabular}




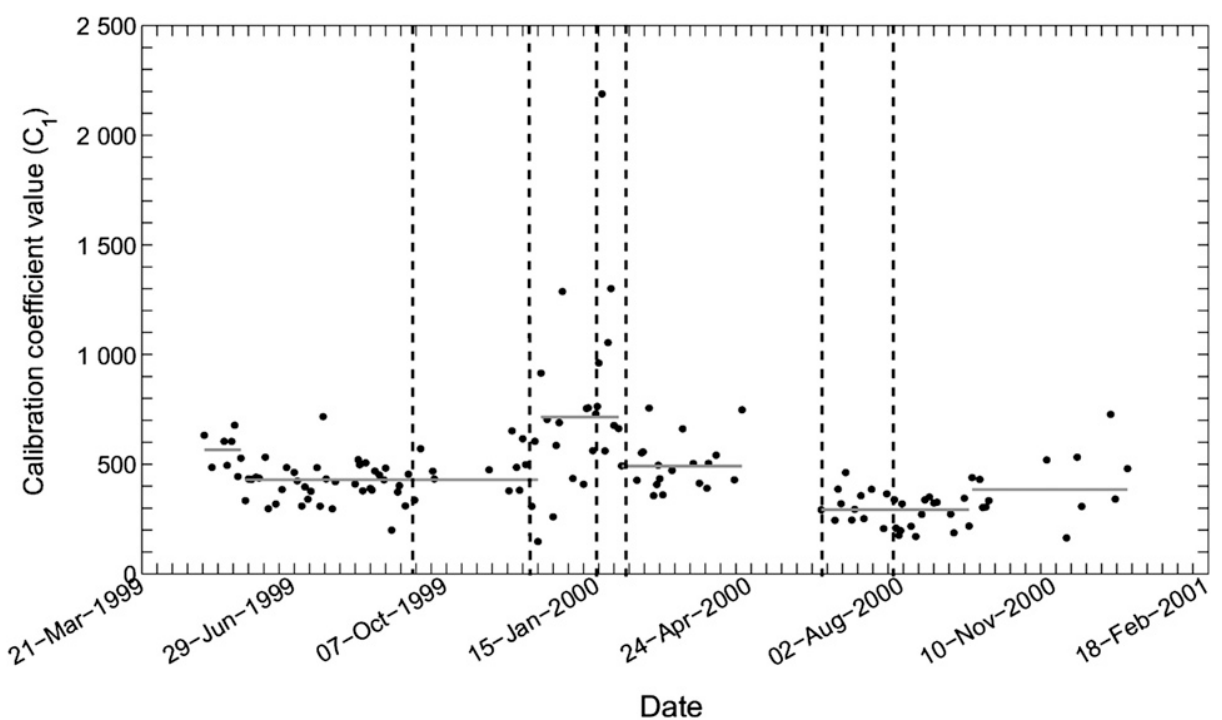

FIG. 9. Calibration coefficient values $\left(C_{1}\right)$ obtained by lidar/radiosonde calibration.

calibrated with the three methods, in the altitude range 2-7 km, has been calculated. The signals observed result in the contribution of geophysical variability with various superimposed errors associated with the instrument (optical fiber transmission, filter efficiency, etc.) and data processing (noise extraction, calibration, etc.). Both contributions being independent, we define the observed variance as the sum of the geophysical variance and the variance of error, $\left(\sigma_{\mathrm{obs}}^{2}=\sigma_{\varphi}^{2}+\sigma_{\text {err }}^{2}\right)$. Because the number of profiles is reasonably large (139), a decrease in the observed variance of the mixing ratio series cali- brated by one or another method could inform one about the reduction of the instrumental discontinuitycalibrated series.

The variance vertical profile of water vapor mixing ratio series without calibration has been compared with the radiosonde method applied in different manners: (i) an individual calibration in which the water vapor mixing ratio profiles are adjusted one by one with individual calibration coefficients and (ii) a calibration that uses the median of the coefficient over the identified periods. To be able to compare variance profiles, the

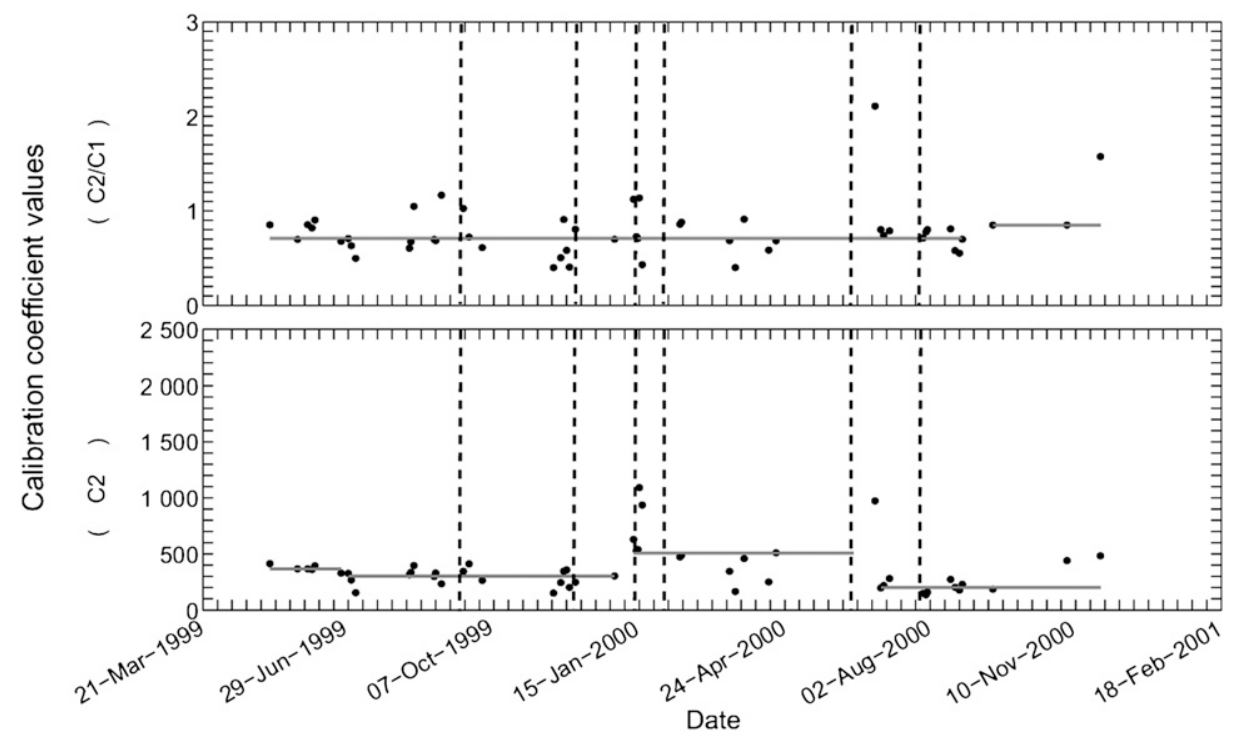

FIG. 10. As in Fig. 9, but for $C_{2}$ obtained by the calibration method coupling radiosonde and total column $\mathrm{H}_{2} \mathrm{O}$. 




FIG. 11. Variance distribution for $C_{1}$ in the altitude range $2-7 \mathrm{~km}$ for May 1999-December 2000.

variance has been normalized by the mean. Also, variance comparison, shown in Fig. 11 has been made using the same individual points because water vapor columns are not available for all cases. The results (Fig. 12) show a reduction of the variance with individual calibration coefficients but a little more so when the medians of the coefficients are used; in this case, a reduction of $10 \%$ of the variance is observed at nearly all heights. The variance profile using the clear-sky zenith calibration method was not reduced as much as the radiosonde method, even if discontinuities have been better detected. This result seems to suggest that our hypothesis - that the system behaves similarly during both nighttime and daytimeis not valid. The method of using the total column is the best one that we have tested, based on the variance weakening. Total column method tends to improve the calibration compared to the radiosonde method, even if the improvement is by only a small percentage. With the number of coefficient values being less important in relation to this method, medians detected are less pertinent than in previous cases, as illustrated in Fig. 10. So, the medians are determined in accordance to the periods



FIG. 12. Variance distribution for $C_{2}$ in the altitude range $2-7 \mathrm{~km}$ for May 1999-December 2000. 
detected by the radiosonde calibration method. For such a short period, the radiosonde humidity sensor has not changed. If so, the total column would have been the best guarantee for being nonsensitive to such instrumental changes.

\section{Conclusions}

We have described a methodology for the study of the distribution of water and its long-term evolution. The proposed methodology relating to the integration time seems to be a good compromise between the accuracy of the lidar profile and variability of water vapor. According to the duration of measurements, from two to five profiles are generally detected with water vapor contents quasi stationary, and the error evolution, principally random error, has been shown to be of a small percentage up to $6 \mathrm{~km}$ and to increase up to $\sim 60 \%$ at $10 \mathrm{~km}$ for a temporal integration of $1 \mathrm{~h}$. An intercomparison between the lidar and the SDLA permits validation of this method, showing good accordance between the two profiles. Concerning the investigation of the calibration methods, it has been shown that the method of using zenith clear-sky observations did not provide results as good as the calibration from radiosonde that improved the calibration, reducing the observed variance of $10 \%$ at all heights. However, the zenith clear-sky observation method seems to be better for the detection of instrumental changes. The results obtained according to these methods suggest that the hypothesis that the system behaves similarly during nighttime and daytime is not valid. Both calibration methods are in agreement with instrumental changes; however, the clear-sky calibration method gives the best results in detecting discontinuities because this method is more sensible and, therefore, more clearly identifies jumps/discontinuities in the calibration coefficient. The illumination conditions of the photomultipliers are different according to daytime sky background calibration that is based on the filter shape or nighttime laser operations related to beam transmission. Also, better results for the calibration have been obtained from the method using the total column, which tends to improve the radiosonde method. Even if extending the lidar profile downward from radiosonde so as to use total column is not an optimal solution, this method seems to be a good compromise in improving the calibration. However, the double-channel system or coaxial configuration is preferred to provide a better vertical coverage and use the total column measurements directly in the calibration.

Acknowledgments. The authors wish to thank the OHP and SA technical team for insuring regular ob- servations and maintenance of the lidar system. Part of the mechanic of the calibration device has been designed and developed by Christian Mollet. Emmanuel Riedinger has implemented the zenith sky calibration method. This instrument was developed with partial support of ADEME under Contract 0562c0054.

\section{REFERENCES}

Bates, B. C., Z. W. Kundzewicz, S. Wu, and J. P. Palutikof, Eds., 2008: Climate change and water. Intergovernmental Panel on Climate Change Tech. Paper 6, 210 pp.

Cooney, J., 1970: Remote measurements of atmospheric water vapor profiles using the Raman component of laser backscatter. J. Appl. Meteor., 9, 182-184.

Davis, A., A. Marshak, W. Wiscombe, and R. Cahalan, 1996: Scale invariance of liquid water distributions in marine stratocumulus. Part I: Spectral properties and stationary issues. J. Atmos. Sci., 53, 1538-1558.

Durry, G., and G. Megie, 1999: Atmospheric $\mathrm{CH}_{4}$ and $\mathrm{H}_{2} \mathrm{O}$ monitoring with near-infrared InGaAs laser diodes by SDLA, a balloonborne spectrometer for tropospheric and stratospheric in situ measurements. Appl. Opt., 38, 7342-7354.

, and, _ 2000: In situ measurements of $\mathrm{H}_{2} \mathrm{O}$ from a stratospheric balloon by diode laser direct-differential absorption spectroscopy at $1.39 \mu \mathrm{m}$. Appl. Opt., 39, 5601-5608.

, and I. Pouchet, 2001: A near-infrared diode laser spectrometer for the in situ measurement of methane and water vapor from stratospheric balloons. J. Atmos. Oceanic Technol., 18, 1485-1494.

Faduilhe, D., P. Keckhut, H. Bencherif, L. Robert, and S. Baldy, 2005: Stratospheric temperature monitoring using a vibrational Raman lidar. Part 1: Aerosols and ozone interferences. J. Environ. Monit., 7, 357-364.

Ferrare, R. A., S. H. Melfi, D. N. Whiteman, K. D. Evans, F. J. Schmidlin, and D. O'C. Starr, 1995: A comparison of water vapor measurements made by Raman lidar and radiosondes. J. Atmos. Oceanic Technol., 12, 1177-1195.

—, D. D. Turner, L. Heilman Brasseur, W. F. Feltz, O. Dubovick, and T. P. Tooman, 2001: Raman lidar measurements of the aerosol extinction-to-backscatter ratio over the Southern Great Plains. J. Geophys. Res., 106, 20333 20347.

Goldfarb, L., P. Keckhut, M.-L. Chanin, and A. Hauchecorne, 2001: Cirrus climatological results from lidar measurements at OHP $\left(44^{\circ} \mathrm{N}, 6^{\circ} \mathrm{E}\right)$. Geophys. Res. Lett., 28, 1687-1690.

Hyland, R. W., and A. Wexler, 1983: Formulations for the thermodynamic properties of the saturated phases of $\mathrm{H}_{2} \mathrm{O}$ from $173.15 \mathrm{~K}$ to $473.15 \mathrm{~K}$. ASHRAE Trans., 89, 500-519.

Kley, D., J. M. Russell III, and C. Philips, Eds., 2000: SPARC assessment of upper tropospheric and stratospheric water vapour. WCRP 113, WMO/TD 1043, SPARC Rep. 2, 312 pp.

Lanzante, J. R., 1996: Resistant, robust and non-parametric techniques for the analysis of climate data: Theory and examples, including applications to historical radiosonde station data. Int. J. Climatol., 16, 1197-1226.

Leblanc, T., and I. S. McDermid, 2008: Accuracy of Raman lidar water vapor calibration and its applicability to long-term measurements. Appl. Opt., 47, 5592-5602.

- - - and R. Aspey, 2008: First-year operation of a new water vapor Raman lidar at the JPL Table Mountain Facility, California. J. Atmos. Oceanic Technol., 25, 1454-1462. 
Moultaka, J., S. A. Ilovaisky, P. Prugniel, and C. Soubiran, 2004: The ELODIE archive. Publ. Astron. Soc. Pac., 116, 693-698.

Platt, C. M. R., and A. C. Dilley, 1984: Determination of the cirrus particle single-scattering phase function from lidar and solar radiometric data. Appl. Opt., 23, 380-386.

Sakai, T., T. Nagai, M. Nakazato, T. Matsumura, N. Orikasa, and Y. Shoji, 2007: Comparisons of Raman lidar measurements of tropospheric water vapor profiles with radiosondes, hygrometers on the meteorological observation tower, and GPS at Tsukuba, Japan. J. Atmos. Oceanic Technol., 24, 1407-1423.

Sarkissian, A., and J. Slusser, 2009: Water vapor total column measurements using the Elodie Archive at Observatoire de
Haute Provence from 1994 to 2004. Atmos. Meas. Tech., 2, 319-326.

Sherlock, V., A. Garnier, A. Hauchecorne, and P. Keckhut, 1999a: Implementation and validation of a Raman lidar measurement of middle and upper tropospheric water vapour. Appl. Opt., 38, 5838-5850.

- A. Hauchecorne, and J. Lenoble, 1999b: Methodology for the independent calibration of Raman backscatter water vapour lidar systems. Appl. Opt., 38, 5816-5837.

Soden, B. J., and J. R. Lanzante, 1996: An assessment of satellite and radiosonde climatologies of upper-tropospheric water vapor. J. Climate, 9, 1235-1250. 